American Journal of Applied Sciences 6 (8): 1539-1547, 2009

ISSN 1546-9239

(C) 2009 Science Publications

\title{
Exponential-Hyperbolic Model for Actual Operating Conditions of Three Phase Arc Furnaces
}

\author{
${ }^{1}$ Mahdi Banejad, ${ }^{2}$ Rahmat-Allah Hooshmand and ${ }^{2}$ Mahdi Torabian Esfahani \\ ${ }^{1}$ Faculty of Electrical and Robotic Engineering, \\ Shahrood University of Technology, Shahrood, Iran \\ ${ }^{2}$ Department of Electrical Engineering, University of Isfahan, Isfahan, Iran
}

\begin{abstract}
Problem statement: The Electric Arc Furnace (EAF) is a non-linear load and creates power quality related problem. Therefore, accurate modeling of the EAF is essential. Approach: In this study, an optimal model for EAF in time domain called exponential-hyperbolic, was proposed to describe the behavior of the EAF for all of the operating conditions and it does not need the initial conditions as they needed for the existing methods of modeling of the EAF. Then, the behavior of the proposed model of EAF on the power system was studied using the PSCAD software. In order to analyze the proposed method, several characteristics for different operating conditions were investigated. Results: In the simulation, the parameters were taken from the EAF of the Mobarakeh Steel Making Company (Isfahan-Iran). The results of the simulation accurately showed the behavior of the EAF of the company. Conclusion: The finding of this study showed that the proposed exponential-hyperbolic model was capable in modeling of EAF for different operating conditions.
\end{abstract}

Key words: Electric arc furnace, furnace modeling, unbalanced voltage, unbalanced current, flicker

\section{INTRODUCTION}

The EAF is inherently nonlinear and time-variant loads and it can cause power quality problems such as voltage flicker, odd and even harmonics as well as unbalanced currents and voltages. These problems should be solved in the EAF. In this regard, an optimal model is necessary to consider the mentioned problems. Also, it should be mentioned that the time response of the EAF has a great effect on power quality.

The dynamic specifications of the EAF at any instant of time are affected by conditions of the furnace at that time and previous instants of the time. The reason for that is when the arc is created, the sudden change in the electrons, ions and gas temperature (that may occur due to sudden change of current) is impossible. Therefore, the sudden change of the current will not lead to sudden change of the arc characteristic. Thus, this phenomenon happens gradually. In fact, there is a hysteresis phenomenon in the dynamic of the arc characteristic due to the effects of the current in the previous instants of time on the present time. In brief, the time response of an electric furnace depends on the length of arc, positions of electrodes and topology the external circuit.
The important issue in the modeling of the arc is the simulation of $\operatorname{arc}^{[1-14]}$. There have been several methods to describe the electric arc. The balanced steady state equations are used $\mathrm{in}^{[1,2]}$. The time domain methods based on the differential equations are presented by in ${ }^{[3-5]}$. The methods used in $^{[6,7,12-14]}$ are based on the lineralized methods and approximation. Other methods such as methods based on frequency response $^{[7]}$, V-I characteristic ${ }^{[9,13]}$, nonlinear differential equations $^{[9,10]}$, are used to analyze electric arc of the furnaces. In the following, the advantages and disadvantages of the mentioned methods are explained briefly.

The equations of steady state are very helpful in computational work. However, it deals only with the balanced three phase currents. It also uses an approximated step model for the waveform of VoltageCurrent Characteristic (VIC) of the EAF. In the time domain analysis, the parameters are determined using the harmonic source voltages and the unbalanced three phase currents. This method also uses an approximated step model for $\mathrm{VIC}^{[4]}$. Other method in analyzing the arc model in time domain is formed based on the CassiMayer equation ${ }^{[5,9]}$. In this method, Cassi and Mayer equations are used for the low and high current of the

Corresponding Author: Mahdi Banejad, Faculty of Electrical and Robotic Engineering, Shahrood University of Technology, Shahrood, Iran 
arc, respectively. In the method of linearization and approximation of the arc voltage is determined using the current of in the V-I characteristics of the $\operatorname{arc}^{[2,13]}$.

When the EAF model in the time domain is compared with the model in the frequency domain ${ }^{[8]}$, it can be concluded that modeling in the time domain is more efficient in studying the arc furnace elements and the EAF performance. However, the frequency domain models are more suitable for harmonic analysis of the external network. The external network is the model of a linear system at each harmonic.

In the above explained methods, there are some limitations such as need to initial conditions for solving the differential equations, balanced operating condition of the three phases of the EAF and use of sophisticated mathematical equations for the estimation of the arc model.

Considering the mentioned limitations, this study presents a new model for the EAF in the time domain. The main aspect of the new model is modeling of the proposed method with a good approximation without need to the initial conditions of the EAF performance. Also, the proposed method can be used to describe the different operating conditions of the EAF and power system. Finally, the proposed method presents a suitable model with a very good approximation for the VIC. In order to increase the accuracy of the load model, a random noise is employed to establish a new model of the furnace load. Then, unbalanced situation of the currents and voltages, the effects of the furnace load and voltage flicker are studied in the new model. It should be noted that in this study directly considers the effect of voltage flickering on the voltage arc furnace, in the frequency range of the human vision (between 4$14 \mathrm{~Hz}$ ). In the simulation of this study, the data belongs to a real EAF taken from Mobarakeh Steel Making Company (Isfahan-Iran).

\section{MATERIALS AND METHODS}

The performance of electric diagram for the EAF: Figure 1 shows the electric diagram of a source which supplies an EAF. In order to change the active input power of the arc furnace, a furnace transformer, $\mathrm{T}_{\mathrm{F}}$, is used. This transformer is connected to point of connection, PC. This transformer is equipped with a tap changer located at the secondary winding. This tap changer varies the voltage of the furnace. The arc furnace is also connected to the point of common coupling, PCC, through the substation transformer, $\mathrm{T}_{\mathrm{S}}$. The simplified diagram of Fig. 1 is shown in Fig. 2.

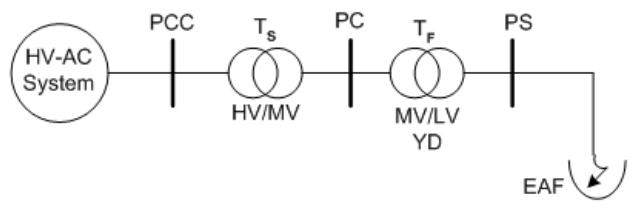

Fig. 1: Diagram of an EAF connected to rest of power system

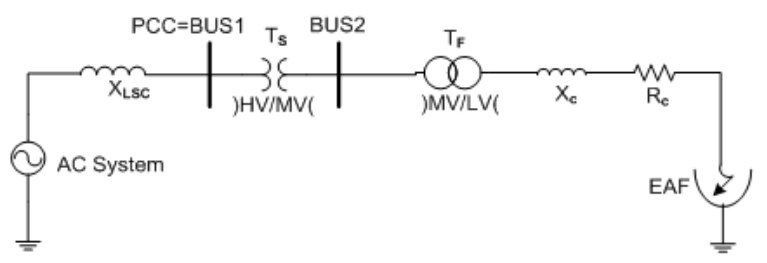

Fig. 2: Circuit diagram of an EAF connected to rest of power system

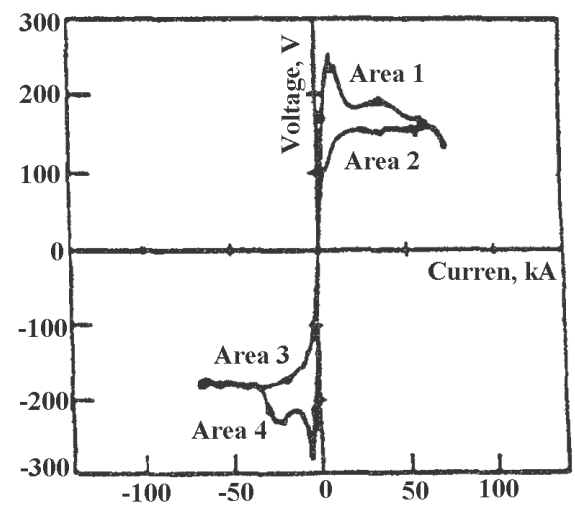

Fig. 3: The Actual V-I model of electric arc furnaces

In Fig. 2, $X_{P}$ is the series reactance for compensation of voltage flicker. The elements of $X_{C}$ and $R_{C}$ are the reactance and resistance of the connected line between furnace electrodes and $\mathrm{T}_{\mathrm{S}}$. This impedance is the dominant part of the total impedance seen by the arc furnace.

Modeling of the EAF's load: In this part, the modeling of the EAF is performed using the estimation of the voltage and current of the electric arc. This modeling is also based on Fig. 3 .

In the other word the modeling is based on the system identification. As can be seen from Fig. 3, the electric arc consists of four major parts as:

Areal $\left\{\frac{\mathrm{di}_{\text {arc }}}{\mathrm{dt}}>0, \quad \mathrm{v}_{\text {arc }}, \mathrm{i}_{\text {arc }}>0\right.$ 


$$
\begin{aligned}
& \text { Area2 }\left\{\frac{\mathrm{di}_{\text {arc }}}{\mathrm{dt}}<0, \mathrm{v}_{\text {arc }}, \mathrm{i}_{\text {arc }}>0\right. \\
& \text { Area3 }\left\{\frac{\mathrm{di}_{\text {arc }}}{\mathrm{dt}}<0, \mathrm{v}_{\text {arc }}, \mathrm{i}_{\text {arc }}<0\right. \\
& \text { Area4 }\left\{\frac{\mathrm{di}_{\text {arc }}}{\mathrm{dt}}>0, \mathrm{v}_{\text {arc }}, i_{\text {arc }}<0\right.
\end{aligned}
$$

According to above equations, Eq. 1 is similar to Eq. 4 and 2 is also similar to Eq. 3. However, the sign of voltage and the current in the similar ones are opposite. Thus, the arc voltage can be expressed as a function of the arc current in their region. In this case we can describe the arc voltage with two different functions. In these descriptions, the arc voltage is dependent on the arc current.

For this purpose in the following, the equations of EAF are analyzed using three different models based on the VIC of the electric arc. Then, the best model among the three models which has description the performance of the furnace is selected.

Model 1: Hyperbolic model: In this model the VIC of the EAF is considered to be in the form of $\mathrm{V}_{\mathrm{a}}=\mathrm{V}_{\mathrm{a}}\left(\mathrm{I}_{\mathrm{a}}\right)$ and it can be described as:

$$
\mathrm{V}_{\mathrm{a}}\left(\mathrm{I}_{\mathrm{a}}\right)=\mathrm{V}_{\mathrm{at}}+\frac{\mathrm{C}}{\mathrm{D}+\mathrm{I}_{\mathrm{a}}}
$$

where, $I_{a}$ and $V_{a}$ are arc current and voltage of phase a. Also, $\mathrm{V}_{\text {at }}$ is the threshold magnitude to which voltage approaches as current increases. This voltage depends on the arc length. The constants $\mathrm{C}$ and $\mathrm{D}$ are corresponding to the arc power and arc current, respectively. These constants can take different values which depend on the sign of the derivative of the arc current. Since Eq. 5 has a behavior similar to hyperbolic function, it is called hyperbolic model. There are two paths to increase or decrease of current. The first path is related to the increasing state of the current and the second path is associated with decreasing state of the current. In this regard, the constants $\mathrm{C}$ and $\mathrm{D}$ are classified into two groups. The constants for the first group (or first path) are $\mathrm{C}_{\mathrm{a}}$ and $\mathrm{D}_{\mathrm{a}}$. Also constants of the second group (or second path) are $\mathrm{C}_{\mathrm{b}}$ and $\mathrm{D}_{\mathrm{b}}$.

Model 2: Complete exponential model: In this model the VIC of the EAF is approximated by an exponential function as follows:

$$
\mathrm{V}(\mathrm{i})=\left\{\begin{array}{lc}
\mathrm{V}_{\mathrm{at}}\left(1-\mathrm{e}^{-\mathrm{i} / \tau}\right), & \mathrm{i} \geq 0 \\
-\mathrm{V}_{\mathrm{at}}\left(1-\mathrm{e}^{-\mathrm{i} / \tau}\right), & \mathrm{i}<0
\end{array}\right.
$$

In the Eq. 6, the current time constant $(\tau)$ is used to describe the positive and negative currents. The exponential function is also used to model the VIC of the arc. This model can be used in optimization and stability issues of the EAF.

Model 3: Proposed model: Exponential-hyperbolic model: In this model the VIC of the EAF described using the following equations:

$$
V(i)= \begin{cases}\mathrm{V}_{\mathrm{at}}+\frac{\mathrm{C}}{\mathrm{D}+\mathrm{i}} & \frac{\mathrm{di}}{\mathrm{dt}} \geq 0, \mathrm{i}>0 \\ \mathrm{~V}_{\mathrm{at}}\left(1-\mathrm{e}^{-\mathrm{i} / \tau}\right) & \frac{\mathrm{di}}{\mathrm{dt}}<0, \mathrm{i}>0\end{cases}
$$

In Eq. 7, $\tau$ is the current time constant in kA. As can be seen as in from this equation, for the positive current and regarding the hysterias property of the arc, there are two cases. To increase and decrease the current of the EAF, the hyperbolic equation and exponential-hyperbolic form of the equation are used, respectively. The proposed method has the capability of describing the EAF behavior in time domain using differential equation ${ }^{[5]}$. In addition, it is able to analyze the behaviors in the frequency domain without solving the sophisticated differential equations.

Moreover, the proposed method can describe different operating conditions of the EAF such as initial melting (scrap stage), mild melting (platting stage) and refinement of the EAF. The results agree with actual conditions of the EAF in the steel industries.

The Unbalanced situation in the proposed method: In order to investigate the effect of unbalanced situations on the proposed exponential-hyperbolic model of load in the EAF, different values for the voltage $\mathrm{V}_{\text {at }}$ in Eq. 7 are considered for different phases. The effect of the different values is more observable at the primary side of PCC. To consider the effect of even harmonics which are produced in the early stage of the charging the furnace, the different values of $\mathrm{V}_{\mathrm{at}}$ are considered for positive and negative part of each phase current.

Investigation the effect of random voltage flicker in the proposed method: In order to study the effect of voltage flicker on the systems with the EAF, it is 
sufficient to consider $\mathrm{V}_{\mathrm{at}}$ in the time-variant form of. This section considers the random variations for the voltage $\mathrm{V}_{\mathrm{at}}$. In this regard, the voltage $\mathrm{V}_{\text {at }}$ is modulated with a random signal at different phases. This signal has the mean of zero with the frequency band in the range of 4-14 Hz. Thus, in this case the voltage $\mathrm{V}_{\mathrm{at}}$ for different phases can be written as

$$
\begin{aligned}
& \mathrm{V}_{\text {at1 }}=\mathrm{V}_{\text {at } 01}+\mathrm{k}_{1} \mathrm{~N}_{1}(\mathrm{t}) \\
& \mathrm{V}_{\text {at } 2}=\mathrm{V}_{\text {at } 02}+\mathrm{k}_{2} \mathrm{~N}_{2}(\mathrm{t}) \\
& \mathrm{V}_{\mathrm{at} 3}=\mathrm{V}_{\mathrm{at} 03}+\mathrm{k}_{3} \mathrm{~N}_{3}(\mathrm{t})
\end{aligned}
$$

where, $\mathrm{N}_{\mathrm{j}}(\mathrm{t}),(\mathrm{j}=1,2,3)$ is a band limited white noise with zero mean and variance of 1 . Also, the modulation index and variance of the random signal are shown by $\mathrm{k}_{\mathrm{j}}(\mathrm{j}=1,2,3)$ and $\mathrm{k}_{\mathrm{j}} \mathrm{N}_{\mathrm{j}}(\mathrm{t})$, respectively. It should be noted that the flicker intensity can be changed by $\mathrm{k}_{\mathrm{j}}$.

\section{RESULTS}

Comparison the different models of the furnace load: In order to compare the proposed exponentialhyperbolic model with the other models, firstly the results of simulations hyperbolic load model are presented. In Model 1, the parameters of EAF characteristics are chosen as:

$$
\begin{aligned}
& \mathrm{V}_{\mathrm{at}}=250 \mathrm{~V} \\
& \mathrm{C}_{\mathrm{a}}=190000 \mathrm{~W} \\
& \mathrm{C}_{\mathrm{b}}=39000 \mathrm{~W} \\
& \mathrm{D}_{\mathrm{a}}=\mathrm{D}_{\mathrm{b}}=5000 \mathrm{~A}
\end{aligned}
$$

The values in Eq. 9 are chosen with respect to a real EAF taken from Mobarakeh Steel Making Company (Isfahan-Iran). Using these parameters, the VIC of the EAF is derived and shown of Fig. 4. The waveforms of the current and voltage of the arc are illustrated in Fig. 5.

The second simulation is associated with exponential model. This model is formed based on Eq. 6. The constant parameters in this model are chosen as:

$$
\begin{aligned}
& \mathrm{V}_{\text {at }}=250 \mathrm{~V} \\
& \tau=10 \mathrm{kA}
\end{aligned}
$$

With the above values for the parameters, the VIC of the arc is obtained as shown in Fig. 6. Also, the waveforms of the current and voltage of the arc are given in Fig. 7.

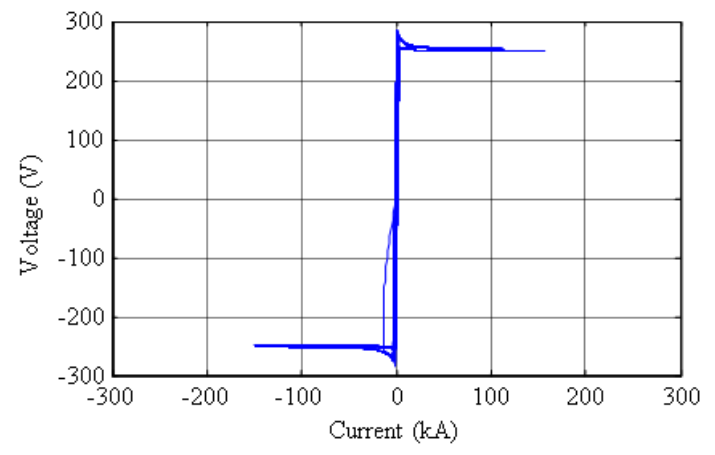

Fig. 4: The VIC of the arc the in the hyperbolic model

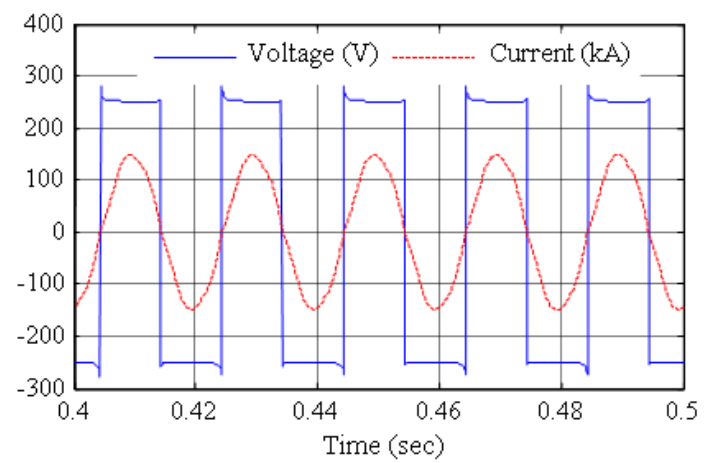

Fig. 5: Waveforms of the arc voltage and current in the hyperbolic model

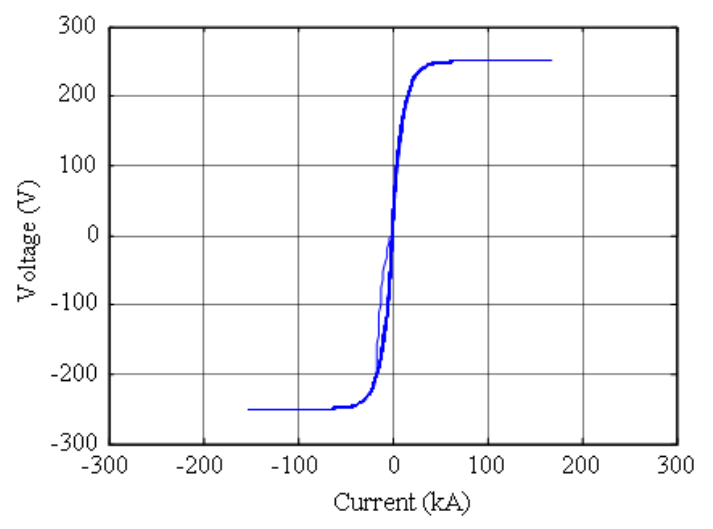

Fig. 6: The VIC of the arc the in the exponential model

Results for the proposed exponential-hyperbolic method: In this part, the results for the proposed exponential-hyperbolic method are studied. In the proposed exponential-hyperbolic model, the parameters are a combination of Eq. 9 and 10. The derived VIC of the arc is depicted in Fig. 8. At the points of this characteristic where the length of the arc is not varied with time, this characteristic is assumed to be constant (at 


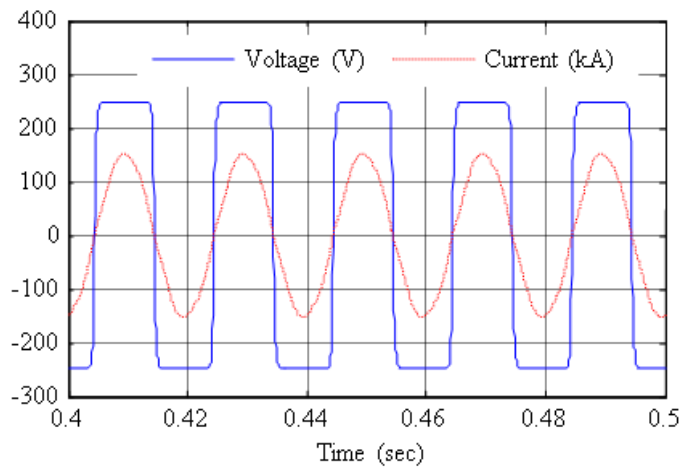

Fig. 7: Waveforms of the arc voltage and current in the exponential model

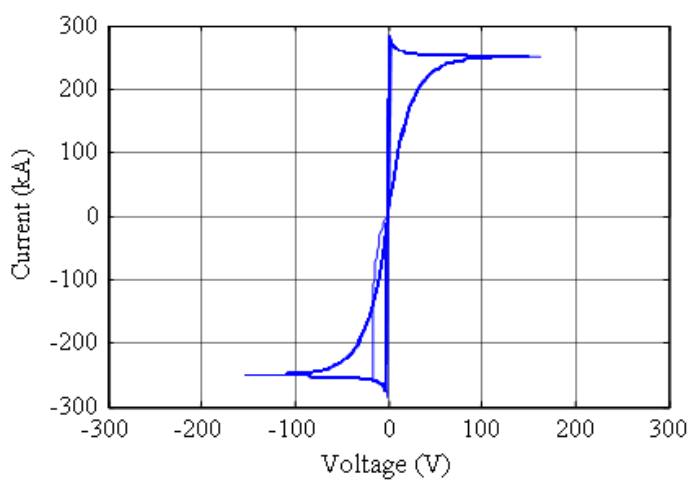

Fig. 8: The VIC of the arc the proposed exponentialhyperbolic model

refining process). In this situation, the EAF does not create any flicker at PCC. At this stage, the EAF produces only odd harmonics in voltage and current, because the VIC has a symmetric behavior. This situation describes the actual performance of the EAF at the plating period. In this period, the level of melting material is nearly constant and the melting is distributed uniformly in the furnace. Figure 9 shows the waveform of voltage and current for the proposed exponential-hyperbolic model of the EAF. Also, the arc conductance and three phase current of the primary side of PCC are shown in Fig. 10 and 11, respectively. The results indicate that if the furnace load does not produce any flicker, then the arc voltage, current and voltage and current of the primary side of PCC oscillate similarly. These waveforms present the actual performance of the electric system supplying the arc system. When the EAF is in the melting process (or scarp stage), the VIC of the arc is in the form of Fig. 12. Finally, for the refining stage of the arc material (at the melt down stage), the VIC of the furnace is given in Fig. 13.

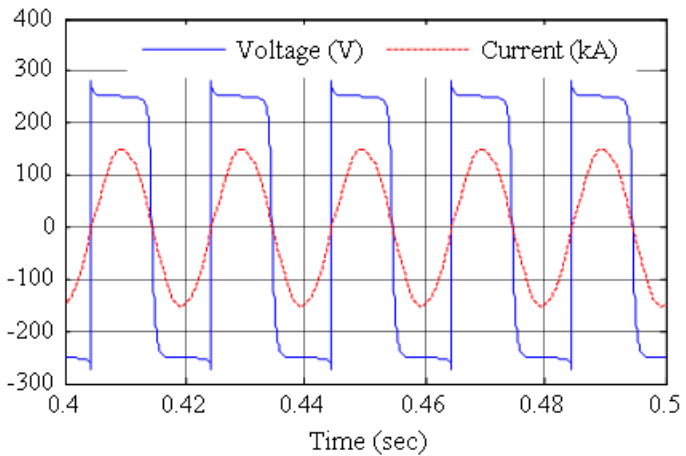

Fig. 9: Waveforms of arc voltage and current in the proposed exponential-hyperbolic model

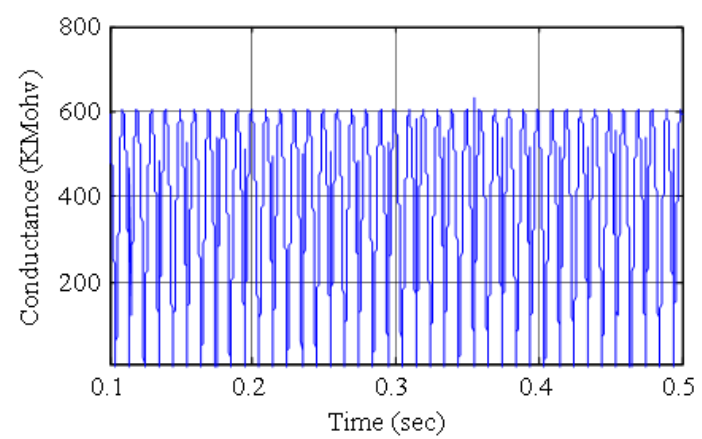

Fig. 10: Waveform of the arc conductance in the situation of the proposed exponentialhyperbolic model

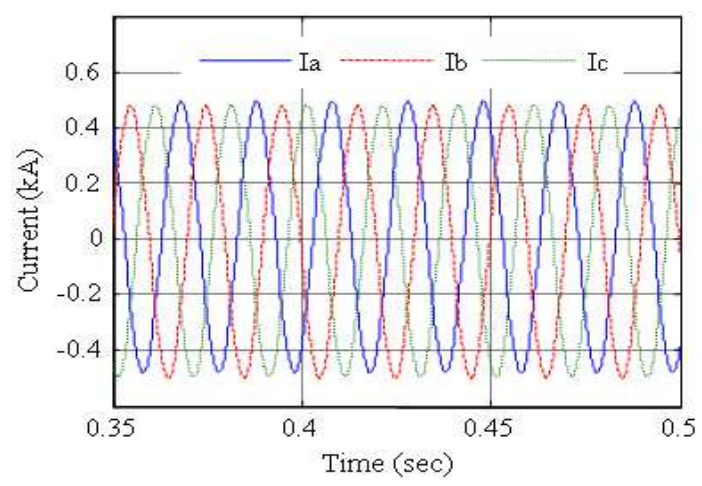

Fig. 11: Waveform of the three phase current at the primary side of the PCC bus in proposed exponential-hyperbolic model

Results for unbalanced three phase furnace load: performance in the unbalance load situation which mostly happens in the initial working condition of the EAF (at the scrap melting stage). 


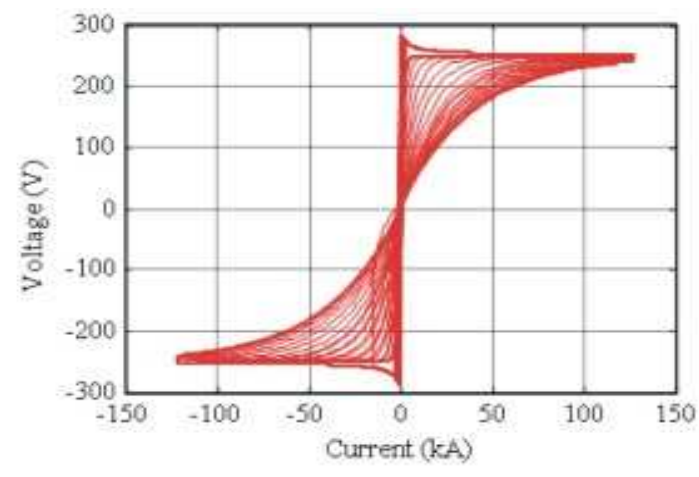

Fig. 12: The VIC of the arc in the scrap stage (or melting process in the proposed exponentialhyperbolic model

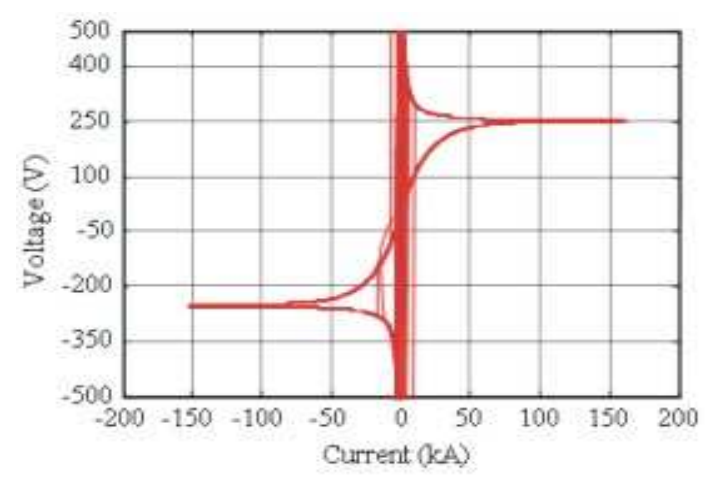

Fig. 13: The VIC of the arc in the refining stage (or melt down process) stage in the proposed exponential-hyperbolic model

In order to study the unbalanced situation in the proposed exponential-hyperbolic model, the voltage $\mathrm{V}_{\text {at }}$ in different phases are considered as:

$\begin{aligned} \mathrm{V}_{\text {ata }} & =250 \mathrm{~V} \\ \mathrm{~V}_{\text {atb }} & =350 \mathrm{~V} \\ \mathrm{~V}_{\text {atc }} & =450 \mathrm{~V}\end{aligned}$

The waveforms of the three phase currents at the primary side are obtained using the values given in Eq. 11. The obtained currents are shown in Fig. 14.

Also, in order to show the even harmonics and asymmetry of the arc, the voltages $\mathrm{V}_{\text {at }}$ for positive and negative current are chosen as:

$\mathrm{V}_{\mathrm{at1}}=250 \mathrm{~V}$

$\mathrm{V}_{\mathrm{at} 2}=120 \mathrm{~V}$

where, $\mathrm{V}_{\mathrm{at1}}$ and $\mathrm{V}_{\mathrm{at} 2}$ are associated with positive current and negative current, respectively. With these values, the waveform of the arc voltage and current are determined and they are shown in Fig. 15.

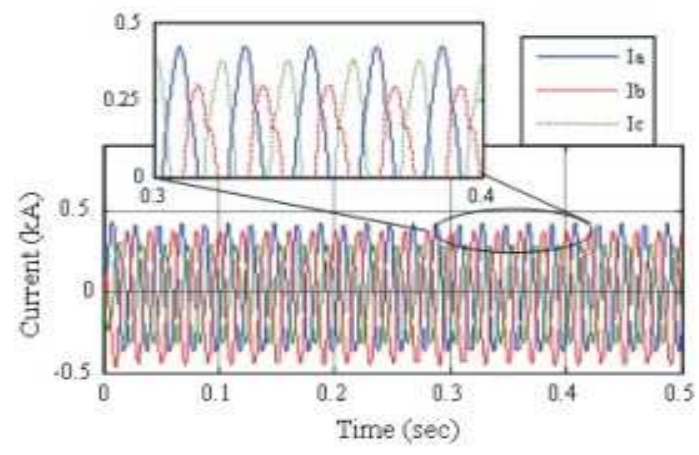

Fig. 14: Waveform of the three phase current at the primary side of the PCC bus in the unbalanced situation for different voltages for three phase in the proposed exponential-hyperbolic model

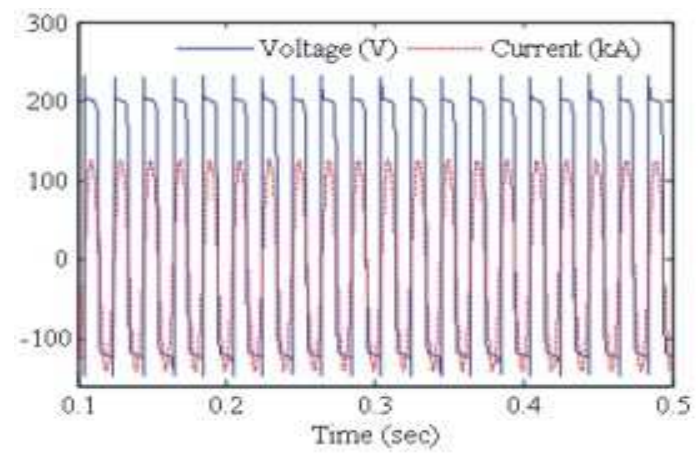

Fig. 15: Waveforms of the arc voltage and current in the case of even harmonics generation with different voltages $\mathrm{V}_{\text {at }}$ in proposed exponentialhyperbolic model

Results for analysis of voltage flicker: In this part, the simulation of the voltage flicker using the random voltage is carried out based on Eq. 8. The values for the parameters used in Eq. 8 are:

$$
\begin{aligned}
& \mathrm{V}_{\mathrm{at01}}=\mathrm{V}_{\mathrm{at} 02}=\mathrm{V}_{\mathrm{at} 03}=250 \mathrm{~V} \\
& \mathrm{k}_{1}=\mathrm{k}_{2}=\mathrm{k}_{3}=1
\end{aligned}
$$

Also in Eq. 8, $\mathrm{N}_{1}(\mathrm{t}), \mathrm{N}_{2}(\mathrm{t})$ and $\mathrm{N}_{3}(\mathrm{t})$ are three white noise voltages with zero mean and variance equals 1 in the limited band (between 4-14Hz).

The results of the simulation are plotted in Fig. 1620. Figure 16 shows the time variations of the random flicker. The VIC of the arc in the situation of random flicker is given in Fig. 17. The arc voltage and current depicted in Fig. 18. Figure 19 shows the waveform of the arc conductance in this situation. Also, Fig. 20 illustrates the waveforms of the three phase current, at the primary side of the PCC bus for the situation. 


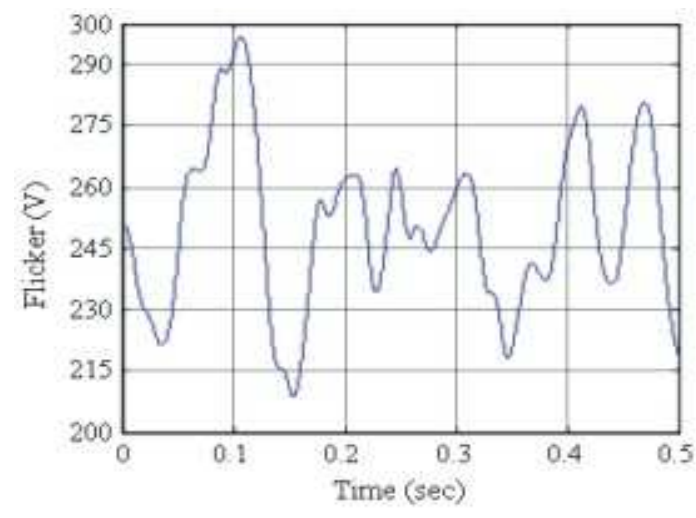

Fig. 16: Waveform of variations of the random flicker

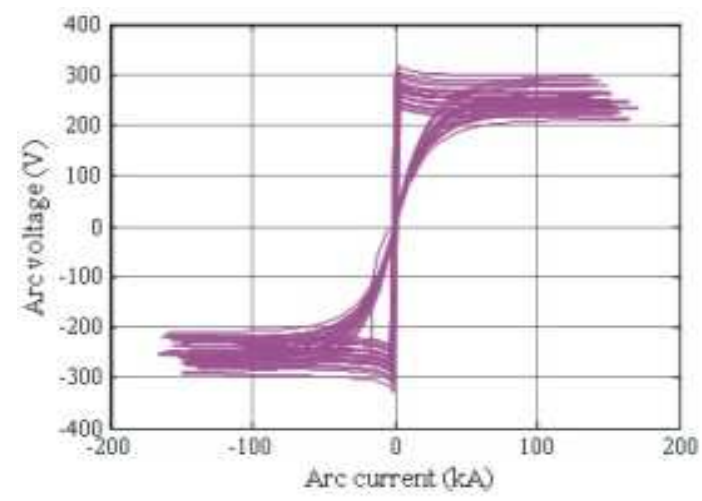

Fig. 17: The VIC of the arc in situation of random flicker

\section{DISCUSSION}

Discussion for the unbalanced three phase furnace load: The simulation results presented in Fig. 14 and 15 shows that when three phases for the furnace load become unbalanced, the three phase currents at the primary side of PCC also becomes unbalanced, remarkably. However, as shown in Fig. 15, the three phase voltages at the primary side of PCC are not nearly changed as shown in Fig. 15. Also, different values for thee phase voltages of the furnace load are chosen in the situations that current increases or decreases, the asymmetry situation occurs of increasing and decreasing current leads to asymmetry in the voltage and current of the furnace. Consequently, this results in producing even harmonics as can be seen in Fig. 15.

Discussion for voltage flicker: Similar to the previous part and based on Fig. 16-20, when the random flicker is applied, the load specifications of EAF are varied randomly. Thus, voltage, current,

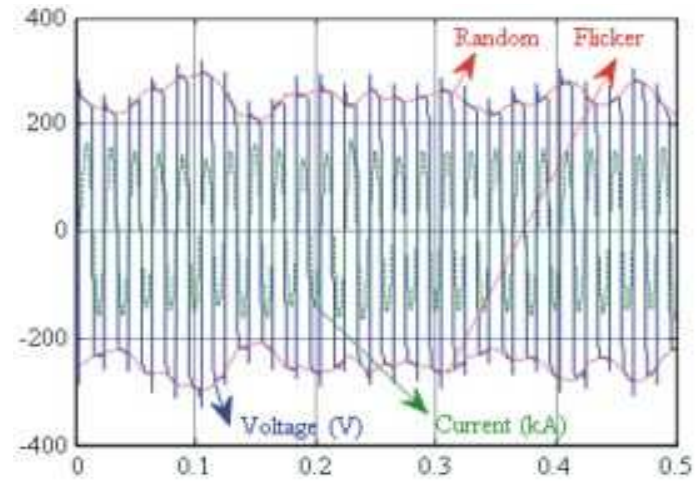

Fig. 18: Waveform of the arc voltage and current in the situation of random flicker

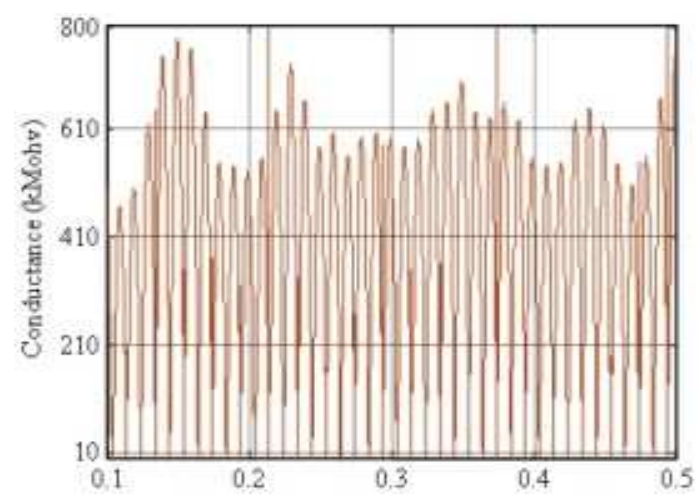

Fig. 19: Waveform of the arc conductance in the situation of random flicker

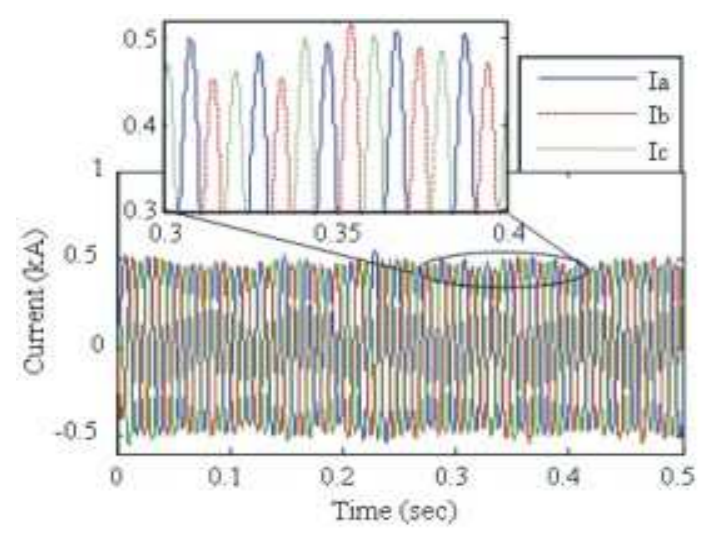

Fig. 20: Waveform of the three phase current at the primary side of the PCC bus in the situation of random flicker

conductance and the three phase current of the primary side of the PCC bus, are varied randomly. However, the variations of the voltage at the primary side of the PCC 
bus are not nearly varied. In the other word, in this case, furnace load flicker leads to a little variation in the voltage of the bus supplying the EAF.

Discussion for harmonic analysis for different models: In this part, the results of harmonic analysis for the different models of the EAF are discussed. Moreover, the effects of furnace load on voltage harmonics are investigated using the proposed exponential-hyperbolic model. So, Table 1 illustrates the generated voltage harmonics at the mild melting stage for the different models; hyperbolic, exponential and proposed exponential-hyperbolic model. Because of the presence of the odd symmetry in the models, no even harmonics is present in the arc voltage.

Also, Table 2 shows the voltage harmonics of the EAF for different operating condition. As can be shown in Table 2, because of lack of odd symmetry in the electric arc, the even harmonics are present in the arc voltage. Thus, these even harmonics are injected to the power system. In addition, when there is a voltage flicker, the harmonics of the electric arc voltage are present. As can be shown in Table 2, the magnitude of harmonics is influenced the type and intensity of the flicker.

Table 1: Comparison of the harmonic magnitude between different models of furnace load in the plate stage (in volt)

Model

\begin{tabular}{lccc} 
Harmonic & Hyperbolic & Exponential & $\begin{array}{l}\text { Bulk d proposed model: } \\
\text { Exponential-hyperbolic }\end{array}$ \\
\hline $\mathrm{H}_{1}$ & 251.62 & 258.32 & 255.33 \\
$\mathrm{H}_{3}$ & 85.18 & 91.34 & 92.22 \\
$\mathrm{H}_{5}$ & 50.71 & 58.68 & 61.57 \\
$\mathrm{H}_{7}$ & 40.55 & 46.91 & 52.33 \\
$\mathrm{H}_{9}$ & 29.42 & 35.12 & 48.19 \\
$\mathrm{H}_{11}$ & 26.33 & 31.32 & 36.52 \\
$\mathrm{H}_{13}$ & 19.12 & 29.34 & 30.13 \\
\hline
\end{tabular}

Table 2: Comparison of harmonic magnitude between different operating conditions with proposed model (in volt)

\section{State}

\begin{tabular}{lccc} 
Harmonic & Balanced & Unbalanced & Random flicker \\
\hline $\mathrm{H}_{1}$ & 251.62 & 255.32 & 261.32 \\
$\mathrm{H}_{2}$ & - & 16.68 & 14.36 \\
$\mathrm{H}_{3}$ & 92.22 & 85.34 & 88.74 \\
$\mathrm{H}_{4}$ & - & 15.91 & 8.65 \\
$\mathrm{H}_{5}$ & 61.57 & 58.36 & 65.26 \\
$\mathrm{H}_{6}$ & - & 15.42 & 8.22 \\
$\mathrm{H}_{7}$ & 52.33 & 40.12 & 49.36 \\
$\mathrm{H}_{8}$ & - & 14.96 & 8.46 \\
$\mathrm{H}_{9}$ & 48.19 & 35.16 & 51.33 \\
$\mathrm{H}_{10}$ & - & 14.55 & 7.98 \\
$\mathrm{H}_{11}$ & 36.52 & 29.11 & 40.34 \\
$\mathrm{H}_{13}$ & 30.13 & 18.51 & 34.61 \\
\hline
\end{tabular}

\section{CONCLUSION}

This study, firstly investigates the existing hyperbolic and exponential models for EAF. After that, the exponential-hyperbolic model is proposed. The proposed model has no limitation of the existing models and does not require any initial conditions or special needs for modeling of the arc. Most of the specifications of the EAF can be described by the proposed method.

This study also proposes a three phase structure of the electric EAF which covers power quality aspects such as: voltage flicker and voltage and current unbalanced situation. Since this model considers the reactance and resistance of the flexible cables, the proposed modeling has high accuracy. The proposed method is simulated on a parameter corresponding to a real EAF and the results of the simulation show the outstanding aspects of the proposed method in well describing the behavior of the EAF when compared to the existing methods.

\section{REFERENCES}

1. Mayordomo, J.G., L.F. Beites, R. Asensi, M. Izzeddine, L. Zabala and J. Amantegui, 1997. A new frequency domain arc furnace model for iterative harmonic analysis. IEEE. Trans. Power Delivery, 12: 1771-1778. http://ieeexplore.ieee.org/xpl/freeabs_all.jsp?arnum ber $=634204$

2. Beites, L.F., J.G. Mayordomo, A. Hernandes and R. Asensi, 2001. Harmonics, interharmonic, unbalances of arc furnaces: A new frequency domain approach. IEEE. Trans. Power Delivery, 16: 661-668.

http://ieeexplore.ieee.org/xpl/freeabs_all.jsp?arnum ber $=956754$

3. Medina, A., M.A. Gomez-Martinez and C.R. Fuerte-Esquivel, 2005. Application of bifurcations theory to assess nonlinear oscillations produced by AC electric arc furnaces. IEEE. Trans. Power Delivery, 20: 801-806. http://ieeexplore.ieee.org/xpl/freeabs_all.jsp?arnum ber $=1413319$

4. Collantes-Bellido, R. and T. Gomez, 1997. Identification and modelling of a three phase arc furnace forvoltage disturbance simulation. IEEE. Trans. Power Delivery, 12: 1812-1817. http://ieeexplore.ieee.org/xpl/freeabs_all.jsp?arnum ber $=634210$

5. Mokhtari, H. and M. Hejri, 2002. A new three phase time-domain model for electric arc furnaces using MATLAB. Proceeding of the Asia Pacific Transmission and Distribution Conference and Exhibition, Oct. 6-10, IEEE Xplore Press, USA., pp: 2078-2083. DOI: 10.1109/TDC.2002.1177781 
6. Postiglione, G. and P. Ladoux, 2006. A new concept of electrical power supply for AC arc furnaces. Proceeding of the IEEE International Symposium on Power Electronics, Electrical Drives, Automation and Motion, May 23-26, IEEE Xplore Press, USA., pp: 619-624. DOI: 10.1109/SPEEDAM.2006.1649845

7. Zhang, Z., N.R. Fahmi and W.T. Norris, 2001. Flicker analysis and methods for electric Arc Furnace Flicker (EAF) mitigation (a survey). IEEE. Porto Power Tech Proc., 1: 1-6. DOI: 10.1109/PTC.2001.964651

8. Gomez-Martinez, M.A., A. Medina and C.R. Fuerte-Esquivel, 2006. AC arc furnace stability analysis based on bifurcation theory. IEE. Proc. Gener. Transm. Distrib., 153: 463-468. DOI: 10.1049/ip-gtd:20050382

9. Lee, Y., H. Nordborg, Y. Suh and P. Steimer, 2007. Arc stability criteria in AC arc furnace and optimal converter topologies. Proceeding of the 22th Annual IEEE Conference on Applied Power Electronics, Feb. 25-Mar. 1, IEEE Xplore Press, USA., $\quad$ pp: $1280-1286 . \quad$ DOI: 10.1109/APEX.2007.357680

10. Petersen, H.M., R.G. Koch, P.H. Swart and R. Van Heerden, 1995. Modeling arc furnace flicker and investigating compensation techniques. Proceeding of the 30th IAS Annual Conference Meeting on Industry Applications, Oct. 8-12, IEEE Xplore Press, USA., pp: 1733-1740. DOI: 10.1109/IAS.1995.530515
11. Varadan, S., E.B. Makram and A.A. Girgis, 1996. A new time-domain model voltage source for an arc furnace using EMTP. IEEE Trans. Power Delivery, 11: 1685-1691. DOI: 10.1109/61.517535

12. Zheng, T. and E.B. Makram, 2000. An adaptive arc furnace model. IEEE. Trans. Power Delivery, 15: 931-939. DOI: 10.1109/61.871355

13. Alonso, M.A.P. and M.P. Donsion, 2004. An improved time domain arc furnace model for harmonic analysis. IEEE. Trans. Power Delivery, 19: 367-373. DOI: 10.1109/TPWRD.2003.820189

14. Ting, W., S. Wennam and Z. Yao, 1997. A new frequency domain method for the harmonic analysis of power system with arc furnace. Proceeding of the IEEE Conference on Advances in Power System Control, Operation and Management, Nov. 11-14, IEEE Xplore Press, USA., pp: 552-555.

http://ieeexplore.ieee.org/xpl/freeabs_all.jsp?arnum ber $=724906$ 